\title{
SAVOY, Bénédicte, Tempel der Kunst. Die Geburt des öffentlichen Museums in Deutschland, 1701-1815
}

\section{Élisabeth Décultot}

\section{OpenEdition}

\section{Journals}

Édition électronique

URL : http://journals.openedition.org/ifha/617

DOI : $10.4000 /$ ifha. 617

ISSN : 2198-8943

Éditeur

IFRA - Institut franco-allemand (sciences historiques et sociales)

Référence électronique

Élisabeth Décultot, «SAVOY, Bénédicte, Tempel der Kunst. Die Geburt des öffentlichen Museums in Deutschland, 1701-1815 », Revue de I'IFHA [En ligne], Date de recension, mis en ligne le 01 janvier 2007 , consulté le 22 septembre 2020. URL : http://journals.openedition.org/ifha/617 ; DOI : https://doi.org/ $10.4000 /$ ifha.617

Ce document a été généré automatiquement le 22 septembre 2020.

(C)IFHA 


\title{
SAVOY, Bénédicte, Tempel der Kunst. Die Geburt des öffentlichen Museums in Deutschland, 1701-1815
}

\author{
Élisabeth Décultot
}

Depuis les ouvrages d'Édouard Pommier ([dir.], Les Musées en Europe à la veille de l'ouverture du Louvre, Paris, 1995), de Klaus Minges (Das Sammlungswesen der frühen Neuzeit. Kriterien der Ordnung und Spezialisierung, Münster, 1998) et de James Sheehan (Museums in the German Art World. From the End of the Old Regime to the Rise of Modernism, Oxford, 2000), l'histoire des musées allemands au XVIIIe s. commence à être mieux connue et, par contrecoup, la nouveauté radicale communément attribuée au Louvre, quelque peu relativisée. L'ouverture, en vertu d'un décret de 1793, d'un musée public, national et républicain au palais du Louvre constitue certes un événement majeur dans l'histoire culturelle européenne, mais cette institution n'a pas été sans précurseurs, notamment dans les pays de langue allemande. C'est à cette préhistoire allemande de l'institution muséale qu'est consacré Tempel der Kunst. Die Geburt des öffentlichen Museums in Deutschland, 1701-1815, dirigé par B.S. Dans la première partie de cet intéressant ouvrage, cinq essais, rédigés par B. SAVOY, É. François, A. VON BUTTLAR, Astrid BÄHR et É. POMMIER, introduisent aux problématiques centrales du volume : incidence de la structure territoriale de l'Empire allemand, morcelé en une multitude d'états, sur la politique muséale des grandes maisons régnantes, création d'une architecture spécifiquement dévolue au musée, introduction progressive du principe d'un accès public aux collections, comparaison avec le Louvre, etc. La seconde partie de l'ouvrage propose un itinéraire à travers les plus importants musées allemands du XVIIIe s. Dans un ordre qui combine logique topographique et progression chronologique sont analysées une douzaine d'institutions qui offrent un accès public à leurs collections de peintures, d'antiques ou accessoirement d'objets relevant de l'histoire naturelle. Cette revue commence en 1701 avec la galerie de peintures des ducs de Brunswick à Salzdahlum, passe par les musées de Düsseldorf, Dresde, Cassel, Potsdam, Vienne, Mannheim, Göttingen et Munich, pour s'achever en 1803 avec la fondation du musée de Mayence, alors que les troupes 
napoléoniennes occupent la rive gauche du Rhin. L'ensemble de ces études spécifiques de musées, signées par treize auteurs différents, obéit à un plan identique, ce qui permet au lecteur d'établir lui-même des comparaisons entre ces divers cas. Sont analysées la construction du bâtiment (conception architecturale, histoire de l'édification, description intérieure et extérieure de l'ensemble), l'histoire des collections (acquisitions, ventes, agents, choix artistiques), les règles de présentation des œuvres (accrochage, classement), la réalisation des inventaires et catalogues, la composition du personnel en charge du musée et enfin les modalités d'accès pour le visiteur. La troisième et dernière partie du volume comprend une anthologie sélective de textes touchant à la réception de ces divers musées durant la période considérée (1701-1815). Si la plupart des collections analysées dans le volume avaient certes déjà fait l'objet d'enquêtes approfondies, l'ouvrage présente le remarquable avantage de les réunir dans un panorama large et synthétique, ce qui permet de les embrasser pour la première fois du regard et contribue par là à ménager au XVIIIe s. allemand une place centrale dans l'histoire européenne de la notion de "musée ". 